REVISTA DE DERECHO UNED, núm. 1, 2006

\title{
EL DIVORCIO INCAUSADO Y LA PATRIA POTESTAD COMPARTIDA DESPUÉS DEL DIVORCIO. DOS INTERESANTES CAMBIOS EN EL DERECHO ESPAÑOL
}

\author{
Maria Bacigalupo dE GIRARD ${ }^{1}$
}

Sumario: 1. AUTONOMÍA DE LA VOLUNTAD EN LAS RELACIONES PERSONALES DE FAMILIA EQUIVALENTE A RESPONSABILIDAD.-2. LA EXPOSICIÓN DE MOTIVOS DE LA LEY 15/2005 LA LIBERTAD COMO EXPONENTE DEL MATRIMONIO Y DEL DIVORCIO.-Del divorcio sanción al divorcio remedio.-El divorcio como consecuencia de la separación de hecho.-3. LA PATRIA POTESTAD COMO FUNCIÓN, NO COMO POTESTAD.-Patria potestad compartida.-El bienestar del hijo.-El sustento del hijo. A mayor compromiso mayor solidaridad.-4. CONCLUSIÓN: LA REPERCUSIÓN DEL NUEVO SISTEMA EN LA SOCIEDAD.

Las últimas reformas operadas en el Código Civil Español con motivo de la ley 15 de 2005 que regula las situaciones de crisis matrimonial y sus efectos con respectos a los hijos, la convierten en una de las más modernas legislaciones en la materia, logrando proyectar por encima de sus disposiciones un enaltecimiento del ejercicio de la autonomía de la voluntad en las relaciones de familia, sin perder de vista la responsabilidad que este ejercicio trae aparejado como dos caras de una misma moneda.

Podemos sintetizar la reforma en dos grandes institutos: el divorcio incausado y la patria potestad compartida por ambos progenito-

${ }^{1}$ Abogada, Profesora de Familia y Sucesiones, Facultad de Derecho de la Universidad de Buenos Aires, Titulo de posgrado en la carrera de Especialización en Derecho de Familia en la Facultad de Derecho de la Universidad de Buenos Aires. Argentina. 
res luego de producida la crisis que ha dado fin al matrimonio, ambos, sin lugar a dudas, refieren a la libertad de los cónyuges tanto en las relaciones de ellos entre si como con respecto a sus hijos menores de edad.

Pero antes de intentar un estudio sobre estos dos temas debemos obligatoriamente referirnos al tema de la autonomía de la voluntad tan mentado en lo que al derecho de familia respecta.

\section{AUTONOMÍA DE LA VOLUNTAD EN LAS RELACIONES PERSONALES DE FAMILIA EQUIVALENTE}

A RESPONSABILIDAD

Es cierto que el derecho de familia se enrola en el área del derecho privado, rama del derecho que hace de la autonomía de la voluntad un paradigma, por lo tanto, que si sostenemos esta posición no podemos negar que dentro de las relaciones familiares habrá ámbitos de libertad. El desafío es saber hasta donde es posible este ejercicio y cual es su límite ya que talla también de manera preponderante el bien llamado "orden público» aquel que mediante normas imperativas regula igualmente las relaciones familiares, limitando la autonomía de las personas en defensa de un interés superior: el grupo familiar, los niños, la vivienda, la alimentación, la salud. Es justo que el estado imponga este límite que no es más que una proclama de protección ya que, como advirtiéramos en párrafos anteriores la verdadera razonabilidad de estos dos extremos se encuentra en la tirante relación entre libertad y responsabilidad.

La autonomía privada está estrictamente vinculada a la libertad y a la intimidad y amparada en las legislaciones por las normas constitucionales. En el derecho argentino esta protección emana del art. 19 de la Constitución Nacional que dice «Las acciones privadas de los hombres que de ningún modo ofendan al orden y a la moral pública, ni perjudiquen a un tercero, están solo reservadas a Dios, y exentas de la autoridad de los magistrados. Ningún habitante de la Nación será obligado a hacer lo que no manda la ley, ni privado de lo que ella no prohíbe». En esa misma norma aparece el referido límite.

Bidart Campos ha afirmado que el derecho a la intimidad y la autonomía de la voluntad presentan similitudes en tanto una y otra imponen un límite al estado, los terceros y la ley y que aquello normado en el artículo referido no queda abroquelado en lo puramente interno, individual, sino que cubre también ciertas relaciones entre dos o 
más personas, ejemplo de ello es la intimidad de la pareja matrimonial. Dice el autor: a toda cabeza sensata le es fácil comprender que lo que marido y mujer hacen o dejan de hacer en su alcoba escapa a toda interferencia de terceros, nada más ni nada menos que por que incumbe y pertenece a la intimidad de $\operatorname{dos}^{2}$.

Así la Corte Suprema de Justicia de la Nación ha afirmado «el derecho a la intimidad protege jurídicamente un ámbito de autonomía individual constituido por los sentimientos, hábitos y costumbres, las relaciones familiares, la situación económica, las creencias religiosas la salud mental y física y, en suma, las acciones, hechos o datos que, teniendo en cuenta las formas de vida aceptadas por la comunidad, están reservadas al propio individuo ${ }^{3}$.

Es decir, no solo los individuos gozan de libertad para regir sus conductas sino que también existe una autonomía de la libertad familiar, inherente al grupo que conforma la familia, que determina pautas y conductas, normas de convivencia y de educación, pactos internos e insitos en la modalidad de cada familia, en pocas palabras sus propias normas internas, las que se van pactando día a día y que rigen en el mundo íntimo que conforma una familia, donde el estado tendrá poca injerencia.

Estas normas internas o autonomía de la voluntad familiar, por otra parte, tienen su control en la seguridad que el estado debe dar al cumplimiento de los tratados internacionales de derechos humanos, incorporados a las Constituciones de los Estados Nacionales, de indudable repercusión en el contenido de las relaciones familiares. Estos principios podrían denominarse «orden público familiar» y suponen la efectividad de principios de solidaridad familiar, igualdad efectiva y protección del más débil. Y justifican la injerencia del estado en el ámbito de las relaciones familiares. En síntesis, no es posible dejar librado en forma total el funcionamiento de la familia a la voluntad de sus componentes, ciertos derechos deben asegurarse a través de reglas imperativas, es decir, el derecho a organizar la vida íntima y personal debe armonizarse con los principios de solidaridad, igualdad efectiva, responsabilidad y protección al más débil.

2 Bidart Campos, Germán J. «Intimidad y autonomía de la voluntad en el derecho de familia ¿ para que hasta donde con que alcance?» Derecho de Familia Revista Interdisciplinaria de Doctrina y Jurisprudencia N. ${ }^{\circ}$ 15, p. 9 Abeledo Perrot, 1999 Buenos Aires Argentina.

3 (CSJN, 13-12-1996 «Estado Nacional c/ Colegio Público de Abogados de la Capital Federal» L.L. 1996-B-35). 


\section{LA EXPOSICIÓN DE MOTIVOS DE LA LEY 15/2005}

\section{LA LIBERTAD COMO EXPONENTE DEL MATRIMONIO Y DEL DIVORCIO}

Habiendo efectuado una primera aproximación al tema de la autonomía de la voluntad se hace ahora imprescindible mencionar algunas notas sobresalientes de la exposición de motivos de la Ley 15 de 2005, la que exalta los conceptos antes vertidos y fundamenta la reforma efectuada en el régimen de disolución del matrimonio y la patria potestad compartida.

La reforma encarada tiene su cimiento en la libertad, tomado este concepto como valor superior del ordenamiento jurídico, el que debe tener su más adecuado reflejo en el matrimonio pues la Constitución Española reconoce que dicha institución jurídica posee una innegable trascendencia ya que contribuye al orden político y la paz social y «es cause a través del cual los ciudadanos pueden desarrollar su personalidad".

Coincidimos plenamente en esta consideración ya que creemos firmemente en la contención que la familia y por ende la unión entre los esposos brinda al crecimiento y desarrollo de las personas, no solo de los cónyuges sino también y fundamentalmente de los hijos.

\section{DEL DIVORCIO SANCIÓN AL DIVORCIO REMEDIO}

Pero ocurre que cuando la armonía en la relaciones familiares desaparece es muy difícil pensar en el desarrollo personal, más bien el conflicto abarca todas las áreas de la vida y conduce a un sentimiento de fracaso. Entonces ya no es el matrimonio el cause de desarrollo esperado sino que se convierte en un enemigo de este desarrollo.

A partir de allí nace la lucha por encontrar la mejor manera para lograr una separación que no despedace a los cónyuges. La legislación ha evolucionado lentamente en ese sentido partiendo en un principio de la única forma posible de separación, el divorcio contencioso con atribución de culpa y sin disolución del vínculo hasta llegar a la posterior y bastante reciente separación de hecho de los cónyuges por un lapso que varía según las diferentes legislaciones y que tiene como corolario la sentencia de di- 
vorcio vincular o separación personal. A grandes rasgos, lo que la doctrina ha llamado divorcio sanción y divorcio remedio, las tensiones entre causales objetivas y subjetivas de separación y divorcio.

Pero sin embargo esta ajustada síntesis olvida las vicisitudes por las que tuvieron que transitar los cónyuges para poder arribar a su separación personal cuando lo único que les estaba permitido era un proceso controvertido en el que había que probar injurias, adulterio, infidelidades, indiferencia, abandono y un sinnúmero de estrategias para conseguir un culpable de la ruptura del matrimonio y nunca la causal podía ser el desamor.

Esta enunciación de causas no comprendían las motivaciones profundas de la ruptura conyugal sino solo las consecuencias visibles de aquella y la necesidad de encasillar circunstancias, aprisionándolas en compartimientos específicos, lo que condujo a la jurisprudencia a fluctuar entre adecuarlas al patrón legal o bien examinar con mayor sutileza la relación entre los esposos para verificar, no ya el episodio impactante sino el modo de comunicación que evidenciaba la imposibilidad de la vida en común. ${ }^{4}$

Con esta sintomatología lo que se lograba no era un proceso en el cual se respetaran las individualidades sino más bien una guerra despiadada entre cónyuges que tenía como final la falta de aceptación de los magistrados como causal autónoma del desquiciamiento del matrimonio la incompatibilidad de caracteres, la falta de entendimiento, el mal carácter, o irascibilidad de uno de los cónyuges que no se tradujera en hechos comprendidos dentro de las causales legales. La necesidad de probar causales llevó a desestimar demandas de divorcio, incluso tratándose de matrimonios definitivamente destruidos. De esta manera, al poner el acento en el síntoma definido por la ley, se omitía valorar un funcionamiento conyugal deteriorado o incluso, inexistente ${ }^{5}$.

La conclusión a la que se arriba es que el pensamiento ideológico del legislador al establecer causales de divorcio taxativas fue restringir la voluntad de los esposos en su decisión de formalizar la ruptura.

${ }^{4}$ Grosman Cecilia P., «El proceso de divorcio. Derecho y realidad» Ed. Abaco, 1985, Buenos Aires, Argentina p. 69.

5 Grosman Cecilia P. ob. Cit p. 70. 


\section{EL DIVORCIO COMO CONSECUENCIA DE LA SEPARACIÓN DE HECHO}

La concepción del divorcio como sanción basada en la idea de que todo conflicto conyugal conducente a la ruptura de la convivencia (con o sin disolución del vínculo conyugal) presupone la comisión por parte de uno o de ambos cónyuges de hechos o actos culpables cuya atribución es incompatible con la prosecución de la vida en común, se contrapone con aquella otra que considera el divorcio un "remedio» a una situación conyugal insostenible. Esta se abre paso de dos maneras diferentes el divorcio por mutuo acuerdo de los cónyuges y la separación de hecho prolongada como antecedente de un pedido unilateral o conjunto de separación personal o divorcio.

Se vio plasmada en el derecho español en la Ley del 7 de Julio de 1981 la que en su momento fue una norma avanzada que permitió poner a España en el mismo plano que otros países del entorno, en particular tomando en cuenta que esa norma imponía un sistema de divorcio remedio al que se podía acceder acreditando una separación previa sujeta a plazos relativamente razonables y no excesivos, al tiempo que admitía la posibilidad de que los cónyuges pudieran acceder a la separación y al divorcio de mutuo acuerdo, a través de un procedimiento rápido, en el que el juez se limitaba simplemente a tramitar y dirigir el procedimiento, comprobando el cumplimiento de los plazos legales ${ }^{6}$.

Pastor Vita sostiene que si bien esta reforma tuvo las ventajas antes descriptas trajo situaciones desfasadas y problemáticas cuando no existía mutuo acuerdo y la separación o el divorcio se producían por la causal de separación de hecho ya que allí se volvían a reproducir los conflictos y divergencias existentes entre los cónyuges. Esto principalmente ocurría cuando la separación de hecho era invocada por uno solo de los cónyuges con la oposición del otro, teniendo como corolario una sentencia que sostenía que la perdida de la affectio maritallis, entendida como perdida del afecto existente al contraer matrimonio y extinción en los cónyuges del deseo de continuar la convivencia debía ser mutua y alegada por ambos ya que si esta era de carácter unilateral no constituiría causa de separación, pues su admisión comportaría la posibilidad de separación sin concurrencia de causa. Así se encontraba dividida la jurisprudencia.

' Pastor Vita, Francisco Javier, "Algunas consideraciones sobre la ley de reforma del Codigo Civil en materia de separación y divorcio" en Revista de Derecho de Familia N. 28 julio-septiembre 2005, Ed. Lex Nova Valladolid España. 
Por ello y volviendo a la exposición de motivos se debe destacar que los principios allí expuestos con respecto a la libertad son los que han imbuido y trasladado ese concepto a las situaciones de divorcio o separación personal, destacando que la ley persigue ampliar el ámbito de libertad de los cónyuges relativo al ejercicio de la facultad de solicitar la disolución de la relación matrimonial, es que el respeto al libre desarrollo de la personalidad justifica reconocer mayor trascendencia a la voluntad de la persona cuando ya no desea seguir vinculado con su cónyuge.

Y ahora citaremos textualmente la parte más trascendente de esta exposición de motivos "Así el ejercicio de su derecho a no continuar casado no puede hacerse depender de la demostración de la concurrencia de causa alguna, pues la causa determinante no es más que el fin de esa voluntad expresada en su solicitud, ni, desde luego, de una previa e ineludible situación de separación». Por ello es que la reforma ha ponderado que basta con que uno solo de los esposos no desee la continuación del matrimonio para que pueda demandar el divorcio, sin que el demandado pueda oponerse a la petición por motivos materiales y sin que el juez pueda rechazar la petición. Solo se requerirá que hayan transcurrido tres meses desde la celebración del matrimonio.

Pero claro, esto debe acompañarse con los convenios que regulen las consecuencias de la separación o divorcio. Aquí es donde volvemos a encontrarnos con el límite de la autonomía de la voluntad: la responsabilidad en la toma de decisiones que no pueda perjudicar intereses también protegidos como se refiriere con antelación: solidaridad, igualdad efectiva, responsabilidad y protección al más débil.

En síntesis la reforma articulada permite que transcurrido el plazo de tres meses de celebrado el matrimonio ambos cónyuges en forma conjunta o uno de ellos con el consentimiento del otro o uno solo de los cónyuges en forma independiente, soliciten judicialmente la separación. En todos los casos se deberá presentar un proyecto de convenio regulador de las consecuencias de la separación.

Este régimen se extiende también a la solicitud de divorcio en los mismos términos expuestos.

En conclusión el sistema español ha abandonado las causales de separación y divorcio. Basta que uno de los esposos no desee la continuación del matrimonio para que pueda demandar el divorcio. El demandado no podrá oponerse, tampoco el juez podrá rechazar la petición. Para la interposición de la demanda, en este caso, solo se re- 
quiere que hayan transcurrido tres meses desde la celebración del matrimonio, salvo que el interes de los hijos o del cónyuge demandante justifique la suspensión o disolución de la convivencia con antelación, y que en ella se haga solicitud y propuesta de las medidas que hayan de regular los efectos derivados de la separación. (Exposición de Motivos)

Merece señalar que es coincidente con la aplicación de los principios de responsabilidad la reforma efectuada por esta misma ley en el art. 68 al incorporar como deber entre los cónyuges durante el matrimonio la obligación de compartir las responsabilidades domésticas y el cuidado y atención de ascendientes y descendientes... Nuevamente un límite a la autonomía de la voluntad basado en la responsabilidad y el cuidado de las personas dependientes del matrimonio.

\section{LA PATRIA POTESTAD COMO FUNCIÓN, NO COMO POTESTAD}

\section{PATRIA POTESTAD COMPARTIDA}

El segundo tema en el que ha operado la reforma es el referente al ejercicio de la patria potestad de los padres con respecto a sus hijos luego de la separación o el divorcio.

Como cuestión previa una referencia a la terminología empleada. Si bien estamos acostumbrados al uso del término patria potestad, literalmente este significa poder del padre y si consideramos que la misma no es un poder sino una función destinada a satisfacer las necesidades del hijo teniendo como preocupación esencial su interés superior, deberíamos intentar trasladar ese significado al término empleado, por eso es que en algunas legislaciones como la inglesa, el Código Civil Francés, el Código de Familia de El Salvador, el Código de la Niñez y la Adolescencia de Paraguay, el Código Civil de Brasil y el Código Civil Uruguayo, entre otros, se ha visto conveniente sustituirlo por "autoridad parental» o mejor aún por "responsabilidad parental» designación más apropiada para traducir la tarea de crianza y formación de los hijos ${ }^{7}$.

Hecha esta aclaración veremos a continuación las vicisitudes de la responsabilidad parental cuando los padres enfrentan un proceso de divorcio.

7 Grosman Cecilia P. «El cuidado compartido de los hijos despues del divorcio o separación de los padres. ¿Utopía o realidad posible? Libro homenaje a Olga Mesa Castilla (en prensa). 
Mientras los padres están juntos las funciones llamadas por los psicólogos nutricias y normativas son acordadas por ellos mismos en forma conjunta y de acuerdo a las necesidades de los hijos, se discuten las discrepancias y se elaboran en el seno de la pareja las soluciones posibles.

Otra cosa diferente ocurre cuando los padres se separan. Dependerá muchísimo de la relación existente entre ellos durante el post divorcio, la que se verá reflejada en los acuerdos a los que podrán llegar sobre la guarda de sus hijos menores y el ejercicio de la autoridad parental. Siguiendo en este tema a Rosalía Bikel decimos que una pareja separada será funcional cuando: a) sus miembros mantengan la alianza parental; b) teniendo un ejercicio independiente de sus deberes y facultades puedan realizar acuerdos conjuntos; c) sus discrepancias no trasciendan el contexto familiar; d) cada uno favorezca el contacto de los hijos con el otro progenitor. Creemos que el ejercicio compartido de la responsabilidad parental favorece esta situación y por ello la reforma operada por la ley 15 de 2005 es altamente satisfactoria. Mientras que cuando la pareja queda estancada, sin poder llegar a la etapa del divorcio emocional la disputa se torna perenne y los hijos son los que terminaran convertidos en el botín de guerra, creándose serios conflictos de lealtades y por ende bloqueándose su desarrollo intelectual emocional ${ }^{8}$.

Las razones por las cuales consideramos que la tenencia compartida es más viable que el ejercicio de la responsabilidad parental por parte del padre conviviente, limitándose el no conviviente a ejercer una adecuada comunicación con el hijo son muchas. Haremos hincapié en algunas de ellas, quizás las más importantes.

\section{EL BIENESTAR DEL HIJO}

En algunas legislaciones tales como la argentina la ley establece que, en los casos de separación de hecho, separación personal, divorcio vincular o nulidad de matrimonio, la titularidad de la patria potestad la tienen ambos padres pero el ejercicio de la función, es decir su faz activa la tiene quien ejerce la tenencia (art. 264 inc. 2 del Código Civil) tanto para el caso de hijos matrimoniales como extramatrimoniales, el otro progenitor solo podrá ejercer un adecuado ré-

${ }^{8}$ BIKEL, Rosalía. "Vicisitudes de la responsabilidad parental a partir del proceso de divorcio" en Derecho de Familia Revista Interdisciplinaria de Doctrina y Jurisprudencia N. ${ }^{\circ}$ 26, pag. 30, Ed. Lexis Nexos, Buenos Aires Argentina. 
gimen de comunicación con sus hijos y controlar o supervisar su educación. Es decir, uno tiene el derecho deber de educar al hijo y el otro, el padre no guardador solo podrá controlar desde afuera, como si fuera un extraño a la relación el modo en que la misma es ejercida.

Es evidente que esta comprensión contraría la idea de participación y colaboración e implica una pérdida para el hijo que vulnera el derecho a ser cuidado y educado por ambos padres.

Este sistema ha sido criticado por la doctrina nacional juzgándolo contrario a la igualdad de derechos y la adecuada equivalencia de responsabilidades de los progenitores en la crianza y educación de los hijos asegurados en diversos tratados de derechos humanos de rango constitucional (en especial la Convención sobre Eliminación de todas las formas de Discriminación contra la Mujer arts. 5b. Y 16d y Convención sobre los Derechos del Niño art. 18.1) ${ }^{9}$.

Un fallo del año 1987 dictado por la Sala F de la Cámara Nacional de Apelaciones en lo Civil de la Capital Federal homologó judicialmente un acuerdo de ejercicio conjunto de la patria potestad con el siguiente argumento "mantener el ejercicio compartido significa sostener, en la conciencia de los progenitores, la responsabilidad que sobre ambos pesa respecto del cuidado y educación de los hijos, no obstante la falta de convivencia; y además, preserva el fin querido por la ley, de que no sea uno sino ambos quienes tomen las decisiones que interesan a la persona o a los bienes de los menores» ${ }^{10}$.

En nuestro país los padres deberán celebrar acuerdos para lograr compartir el ejercicio de la responsabilidad parental una vez separados ya que este sistema no se encuentran previsto en el ordenamiento jurídico, los que dependerán de la homologación judicial.

Por lo expuesto es que creemos que se produce un gran avance en los ordenamientos nacionales cuando se encuentra plasmado como en el español la posibilidad de que los padres tomen la decisión de continuar con el ejercicio compartido de la autoridad parental luego de la separación o del divorcio.

9 Azpiri, Jorge «El orden público y la autonomía de la voluntad en la patria potestad» en Derecho de Familia Revista Interdisciplinaria de Doctrina y Jurisprudencia N. ${ }^{\circ}$ 15, pag. 95, Abeledo Perrot, Buenos Aires Argentina.; ZANNONI, Eduardo Derecho de Familia Astrea 1998 T 1 p. 69 Buenos Aires Argentina; Mizrahi, Mauricio, Familia, Matrimonio y Divorcio, Astrea, Buenos Aires Argentina 1998, pag. 424, entre otros.

10 CNCiv, Sala F 23/10/87 La Ley 1989-A-94. 


\section{EL SUSTENTO DEL HIJO. A MAYOR COMPROMISO MAYOR SOLIDARIDAD}

Así podríamos definir este capítulo que está íntimamente entrelazado con el ejercicio de la responsabilidad parental. Por que ocurre que cuando el padre no conviviente pierde la cotidianeidad con sus hijos también va perdiendo poco a poco la responsabilidad en lo que a su sustento se refiere.

Quizás debamos ver las situaciones desde el otro lado del espejo y no como se reflejan en él. Quiero con esto decir que muchas veces es necesario ponerse en el lugar del padre no conviviente para poder explicar como ese padre bueno y atento durante la convivencia con sus hijos se ha convertido, luego de la separación, en un padre poco preocupado por sus necesidades, impuntual y mal pagador.

Cual es el motivo de este alejamiento y desentendimiento de sus responsabilidades. Creemos que justamente lo es la imposibilidad creciente de ir haciéndose cargo también de la decisiones, convirtiéndose únicamente en un proveedor de dinero para la manutención de sus hijos.

En nuestro país los jueces han sostenido que las tareas de carácter personal que realiza la madre a cargo de los niños tiene un valor económico y constituye un aporte a su manutención de singular importancia, por consiguiente en estos casos, es el padre a quien corresponde proveer de manera principal los alimentos para sus hijos, sin perjuicio de que se tome en cuenta los ingresos de la madre para fijar la prestación.

Así es que paulatinamente la madre va asumiendo mayores responsabilidades y el padre se va alejando de sus hijos. En general esta actitud se toma como ejemplo para determinar que es el hombre el que no da cumplimiento a sus obligaciones, el que se desentiende del bienestar de ellos, haciendo cargar sobre las espaldas de la mujer no solo ya el cuidado personal de los mismos sino también la búsqueda de recursos económicos para mantenerlos.

Por lo hasta aquí expuesto es que creemos que debemos mirar el anverso del espejo, es decir, esta es la realidad que se refleja a simple vista, pero no es la que subyace en lo hondo de la relación padre hijo. Lo que ha ocurrido es que se ha perdido el Norte, se le ha quitado al padre toda posibilidad de decisión en el destino de sus hijos y esto ha ido socavando la relación, desvinculando al hijo de una de las figuras parentales, el padre, con lo cual se lesiona su proceso de crecimiento 
y humanización. El hombre convertido en un padre «intermitente», marginado de la familia, poco a poco se distancia de sus hijos, le cuesta recuperar el lugar que tuvo como padre y deja de lado paulatinamente su responsabilidad alimentaria. De modo simétrico, el hijo tiene dificultades en mantener una relación estrecha con ese hombre que ve de manera esporádica, a la vez que percibe el abandono paterno. La escena familiar se cierra con una madre agobiada por las tensiones psíquicas que afronta en soledad la crianza y manutención de sus hijos. Todos los protagonistas son víctimas de esta interacción perniciosa, que atenta contra los principios de la Convención sobre los Derechos del Niño que comprometen a ambos padres en el cumplimiento de los deberes parentales ${ }^{11}$.

Este modelo que hace preponderar la voluntad de uno solo de los progenitores, en la mayoría de los casos la madre, rompe el esquema de la coparentalidad, mientras que la tenencia compartida, entendiendo como tenencia el ejercicio de la responsabilidad parental permite el contacto permanente del niño con ambos padres y al asunción de semejantes responsabilidades en uno y otro.

Citamos como ejemplo de esta definición un fallo dictado por el Superior tribunal de Tierra del fuego que dice «la tenencia compartida o alternada podrá articularse mediante convenios a través de los cuales los interesados buscan compartir de una manera mas o menos igualitaria el trato y responsabilidad respecto de la formación educativa de los hijos, destacándose la participación de ambos padres en la ejecución de los atributos emergentes de la patria potestad, con el objetivo de garantizar el contacto permanente del menor y brindar un modelo de organización familiar que se asemeje a la familia intacta» ${ }^{12}$.

\section{CONCLUSIÓN: LA REPERCUSIÓN DEL NUEVO SISTEMA EN LA SOCIEDAD}

Para concluir, el ejercicio de la responsabilidad parental compartida revela una lógica de participación durante la vida en común que, va de suyo, no debe ser aniquilada por la separación de los padres, por consiguiente, el modelo de guarda y cuidado compartido de los hijos después de la ruptura de la pareja es el sistema que con mayor coherencia se concilia con el principio igualitario y con los cam-

${ }^{11}$ Grosman Cecilia P. «El cuidado compartido de los... op. cit.

12 ST Tierra del Fuego, Antártica e Islas del Atlántico Sur LL, 1998-F-569. 
bios que se han producido en los roles establecidos en función del sexo. La guarda unipersonal es contraria a los principios de igualdad y de responsabilidad que deben imperar en el seno de la familia.

Es que por más dificultades que se encuentre en la práctica de este sistema, que sin lugar a dudas deben ser muchas, se debe priorizar la participación de ambos padres en la educación y crianza de sus hijos y alejar el fantasma instalado ya en la sociedad que las parejas que se han separado no son capaces de compartir el cuidado de sus hijos.

En palabras de Cecilia P. Grosman «Orientar desde la ley el camino hacia un actuar conjunto y solidario de los padres, entrelaza el interés social que aspira a la mejor formación de las nuevas generaciones y el interés individual de los que integran el núcleo familiars ${ }^{13}$.

Por ello y teniendo en cuenta el papel educativo que tiene la ley y más aún el de los jueces que intervienen en el proceso, el hecho de que no solo los padres puedan arribar a este tipo de acuerdos sino que los magistrados puedan contribuir a instalarlos en el seno de la familia es altamente alentador para el desarrollo de esta institución.

Las dos reformas efectuadas enrolan al derecho español entre los más progresistas de occidente, el tiempo dirá cual será el efecto que provoca dentro de la sociedad, es un ejemplo de armonía entre libertad y responsabilidad y nos queda solo desearle éxito en su reglamentación y ejercicio.

13 Grosman Cecilia P. «El cuidado compartido de los... op. cit. 